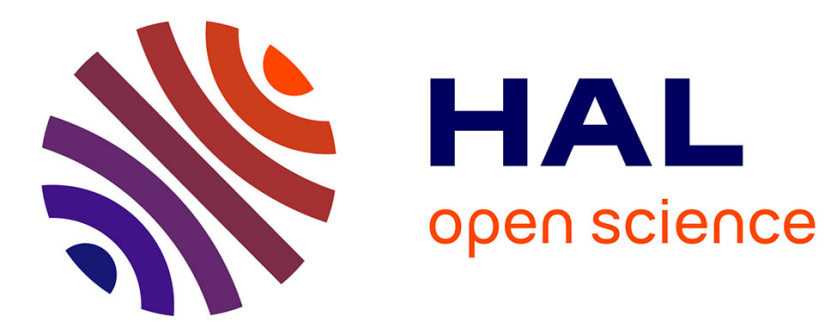

\title{
Mobility of organic pollutants in soil components. What role can magic angle spinning NMR play?
}

\author{
Cécile Chamignon, Nicolas Haroune, Claude Forano, A.M. Delort, Pascale \\ Pascale Besse, P. Besse-Hoggan Besse-Hoggan, Bruno Combourieu
}

\section{To cite this version:}

Cécile Chamignon, Nicolas Haroune, Claude Forano, A.M. Delort, Pascale Pascale Besse, P. BesseHoggan Besse-Hoggan, et al.. Mobility of organic pollutants in soil components. What role can magic angle spinning NMR play?. European Journal of Soil Science, 2008, 59, pp.572-583. hal-00354291v2

\section{HAL Id: hal-00354291 \\ https://hal.science/hal-00354291v2}

Submitted on 10 Mar 2009

HAL is a multi-disciplinary open access archive for the deposit and dissemination of scientific research documents, whether they are published or not. The documents may come from teaching and research institutions in France or abroad, or from public or private research centers.
L'archive ouverte pluridisciplinaire HAL, est destinée au dépôt et à la diffusion de documents scientifiques de niveau recherche, publiés ou non, émanant des établissements d'enseignement et de recherche français ou étrangers, des laboratoires publics ou privés. 


\title{
Mobility of organic pollutants in soil components. What role can magic angle spinning NMR play?
}

\author{
C. Chamignon ${ }^{\text {a }}$, N. Haroune ${ }^{\text {a }}$, C. Forano $^{\text {b }}{ }^{\text {, A.-M. Delort }}{ }^{\text {a }}$, P. Besse-Hoggan ${ }^{\text {a }}$ \& B. \\ COMBOURIEU $^{\mathrm{a}}$ \\ ${ }^{a}$ Laboratoire de Synthèse et Etude de Systèmes à Intérêt Biologique, UMR 6504 CNRS, Université Blaise \\ Pascal, Clermont-Ferrand, F-63177 Aubière Cedex , and ${ }^{\mathrm{b}}$ Laboratoire des Matériaux Inorganiques, \\ UMR 6002 CNRS, Université Blaise Pascal, Clermont-Ferrand, F-63177 Aubière Cedex, France \\ B. Combourieu. E-mail: bruno.combourieu@univ-bpclermont.fr
}

\begin{abstract}
The adsorption-desorption mechanisms at the interface between organic and inorganic soil colloids influence the movement of pesticides and hence their bioavailability and biotransformation processes. Direct analyses of soils have been reported in the literature with the use of solid-state nuclear magnetic resonance (NMR) spectroscopy on dry samples. We recently demonstrated the potential of the ${ }^{1} \mathrm{H}$ high resolution magic angle spinning (MAS) NMR technique to study such mechanisms in situ on highly hydrated samples. By using a well-characterized soil model, it was possible to distinguish the mobile and immobile pesticide unambiguously. In the present communication, a short review of MAS NMR techniques that allow covalent and non-covalent bond analysis is provided. The results obtained in our group on the adsorption of some pollutants such as phosphonomethylglycine (glyphosate), MCPA and 2benzothiazole sulphonate are also presented. Specifically, we focus on the potential of MAS NMR spectroscopy for probing the behaviour (mobility) of these organic pollutants loaded onto the surface of different clays. The influence of clay hydration on NMR spectra has also been evaluated.
\end{abstract}

\section{Introduction}

The fate of organic pollutants in the environment is strongly dependent on the interactions they can make with organic (humic and fulvic acids) and inorganic (clays, metal (hydr)oxides) soil constituents (Cornejo \& Jamet, 2000). The strength of these interactions controls not only the potential of the pollutant to reach groundwater but also its bioavailability towards microorganisms or plants. Numerous studies have documented the key role of organic matter in the sorption of non-polar compounds (Spark \& Swift, 2002, and references cited therein). However, clay particles, due to their small size $(<2 \mu \mathrm{m})$, large surface area $\left(100-800 \mathrm{~m}^{2} \mathrm{~g}^{-1}\right)$, ion exchange properties and open layered structure, can also make a considerable contribution to the pollutant sorption process (surface and inter-crystallite adsorption, intercalation or irreversible grafting), especially when the pollutant is polar (even weakly so) (Gilchrist et al., 1993; Laird $\&$ Sawhney, 2002). Indeed, adsorption properties of soils are mainly due to phyllosilicates, hydrated oxides and hydroxides either in their natural state or associated with humic substances (Matthes \& Kahr, 2000; Laird, 2004; Vereecken, 2005; Gimsing et al., 2007).

When covalent bonds are created, the pollutant forms bound residues with soil that are no longer extractable or bioavailable. It can participate in the humification process or induce some eco-toxicological problems. The pollutant can also interact with weak bonds; in that case it is likely to be more bioavailable for microbes or plants or be transported to ground water. Studying these interactions at a molecular level or, more macroscopically, studying the mobility of the pollutant is not an easy task.

Nuclear magnetic resonance (NMR) spectroscopy is a useful method to assess molecular mechanisms. Most of the studies published are focused on organic matter (OM) composition in terms of its geographical origin and/or the treatment to which it has been submitted by using the classical ${ }^{13} \mathrm{C}$ crosspolarization magic angle spinning (MAS) solid state NMR sequence. Comparatively, the behaviour of organic pollutants in soils or soil fractions has been less studied. Nevertheless, various NMR approaches have been developed to study covalent and non-covalent interactions between pollutants and soil (Nanny et al., 1998; Combourieu et al., 2005). It should be noted that, due to the relatively low sensitivity of NMR techniques, reported studies were carried out exclusively under laboratory and not under field conditions, usually with ${ }^{13} \mathrm{C}$ or ${ }^{15} \mathrm{~N}$-labelled compounds to allow specific detection of residues resulting from covalent bonding (the concentration of the organic pollutant compared with the amount of soil organic matter is very small). This limitation explains why only a few types of compound have been studied to date. $1 \mathrm{D}$ and $2 \mathrm{D}{ }^{15} \mathrm{~N}-{ }^{13} \mathrm{C}$ DCP-MAS (double cross polarization magic angle spinning) NMR 
techniques, which allow specific identification of ${ }^{13} \mathrm{C}$-NMR signals of ${ }^{13} \mathrm{C}$ atoms directly bound to ${ }^{15} \mathrm{~N}$ atoms, have been used successfully to give evidence of covalent bonds between ${ }^{15} \mathrm{~N}$-TNT (trinitrotoluene) and carboxylic and methyl groups of humic acids (Knicker, 2003). This technique is extremely powerful and novel but remains limited by its poor sensitivity.

Non-covalent interactions imply a rather high degree of mobility of the molecules, which are usually in a hydrated environment. Consequently, the various strategies to study these interactions are aimed at assessing this mobility.

First, an indirect approach consists of establishing correlations between organic carbon normalized sorption coefficients (Koc values) of organic pollutants with soil matrices and structural elements of soil organic matter $(\mathrm{OM})$. These correlations should, in principle, allow extrapolation to possible interactions between a pollutant and soil OM. NMR only plays a role in determining the structural groups of OM. The techniques used are mainly CPMAS ${ }^{13} \mathrm{C}$ NMR at natural abundance, but also liquid state ${ }^{13} \mathrm{C}$ NMR for model compounds (Golding et al., 2005; Oren \& Chefetz, 2005; Ahmad et al., 2006; Smernik et al., 2006; Bonin \& Simpson, 2007). However, many of these correlations are unsatisfactory when the pollutant bears polar functions and depend on the percentage or the nature of the OM present.

A second approach takes advantage of NMR properties connected to the orientation or movement of the molecules. For instance, because of the specific properties of the ${ }^{2} \mathrm{H}$ nucleus, ${ }^{2} \mathrm{H}$ MAS-NMR spectra can be used as 'fingerprints' of orientation and movement of ${ }^{2} \mathrm{H}$-labelled pollutants within a solid matrix. This approach is based on the comparison of experimental and simulated spectra (Emery et al., 2001) and this technique requires labelled compounds.

The $T_{1}$ relaxation time is basically an NMR parameter that reflects the intrinsic mobility of each atom, as $\mathrm{T}_{1}$ is inversely proportional to the correlation time, $\tau_{\mathrm{c}}$. In other words, the greater $\mathrm{T}_{1}$, the more mobile the atom. Decrease in $T_{1}$ reflects a stronger interaction between the pollutant and the matrix (Nanny \& Maza, 2001).

A last class of NMR experiment carried out on hydrated solid matrices (peat, soil, clay), which can be considered as more relevant to real environmental conditions, allows study of molecular species at the liquid/solid interface. Basically, the NMR signals detected reflect the degree of mobility of these species: highly mobile molecules give narrow signals, similar to liquid state NMR spectra; in contrast, when the strength of the interaction increases, the signals become progressively broader. Reported studies in this field have been performed at natural abundance on certain pollutants, without labelling them, using ${ }^{19} \mathrm{~F}$ or ${ }^{31} \mathrm{P}$ (efficient but restricted to those containing at least one such atom) (Kohl et al., 2000; Seger \& Maciel, 2006) or ${ }^{1} \mathrm{H}$ NMR. The ${ }^{1} \mathrm{H}$ is present in almost all organic pollutants and has the greatest sensitivity. Therefore, ${ }^{1} \mathrm{H}$ NMR is the most promising for general application. In the past, its use was very restricted because of the narrow range of chemical shifts, the interference with other protons of the matrix and the strong dipolar coupling constants, which gave very broad lines when ${ }^{1} \mathrm{H}$ solid-state NMR was used. The very recent development of the ${ }^{1} \mathrm{H}$ HR-MAS (high resolution magic angle spinning) technique combined with specific HR-MAS probes that allow the use of gradients and shimming coils, opens a new field in environmental studies. Basically, this technique allows the characterization by NMR of inhomogeneous compounds with liquid-like dynamics (Piotto et al., 2001; Simpson et al., 2006). It has also been applied to study the interactions of pesticides with soil (Simpson et al., 2001) or clay (Combourieu et al., 2001). Interactions between pesticides and the surrounding soil matrix, swollen in water, could be observed despite the massive presence of water in the samples.

The purpose of the present communication is to evaluate the potential of MAS NMR spectroscopy for probing the behaviour (mobility) of organic pollutants loaded onto the surface of different clays: cationic (montmorillonite) and anionic (hydrotalcite-like materials, named layered double hydroxides or LDHs). The influence of clay hydration on NMR spectra has also been evaluated. Our NMR results are compared with those obtained with Fourier transform infrared (FTIR) spectroscopy and X-ray diffractometry. Three ionic organic pollutants have been chosen: two well-known and widely used herbicides (4-chloro-2methylphenoxyacetic acid (MCPA) and N-phosphonomethylglycine (glyphosate)) and an industrial pollutant of the widely used benzothiazole family: 2-benzothiazolesulphonate $\left(\mathrm{BTSO}_{3}\right)$ (Figure 1). Benzothiazoles (BTs) have many applications: fungicides in lumber and leather production, antialgal agents, slimicides in the paper and pulp industry, chemotherapeutic agents, and vulcanisation catalysts (see De Wever et al., 2001). $\mathrm{BTSO}_{3}$ is a by-product of an industrial process but is also released from manufactured compounds that contain BTs. Therefore, $\mathrm{BTSO}_{3}$ has been detected not only in industrial 
wastewaters but also in various environmental compartments (Reemtsma et al., 2006). In the case of $\mathrm{BTSO}_{3}$, the potential of MAS NMR to monitor its biotransformation in situ by the bacterial strain Rhodococcus erythropolis in the presence of anionic clays is presented.
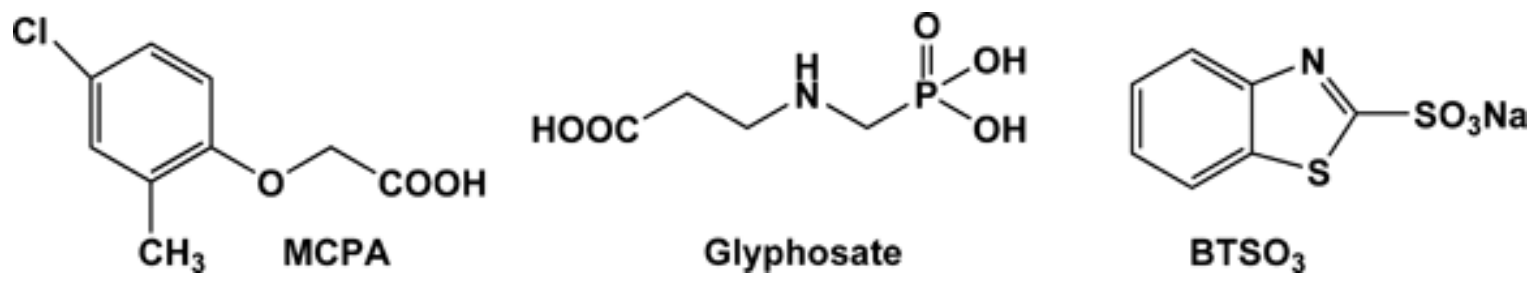

Figure 1 Chemical structures of 4-chloro-2-methylphenoxyacetic acid (MCPA), N-phosphonomethylglycine (glyphosate, $\mathrm{PMG}$ ) and 2-benzothiazolesulphonate $\left(\mathrm{BTSO}_{3}\right)$.

\section{Materials and methods}

\section{Chemicals}

$\mathrm{BTSO}_{3}$ was donated by Bayer (Antwerp, Belgium); N-phosphonomethylglycine (95\%) was purchased from Aldrich (Saint-Quentin Fallavier, France); MCPA (sodium salt) was purchased from Fluka (L'Isle d'Abeau, France); and tetradeuterated sodium trimethylsilylpropionate $\left(\mathrm{TSPd}_{4}\right)$, hexadeuterated sodium 3trimethylsilyl-1-propanesulphonate (DSS) and $\mathrm{D}_{2} \mathrm{O}(99 \%)$ were purchased from Eurisotop (Saint Aubin, France).

\section{Preparation and characterization of clay samples}

Montmorillonite KSF was purchased from Aldrich (batch no. 28,153-0), and the LDHs were prepared in the laboratory as described by Inacio et al. (2001). The mineralogical composition of clays was determined by X-ray diffractometry ( $\mathrm{CuK \alpha}$ radiation; Philips X'Pert automated X-ray diffractometer). The samples were step-scanned in increments of $0.08^{\circ} 2 \theta$ and 4 s per step counting time. Powder XRD patterns were recorded in order to determine whether pollutants were intercalated in the layers or adsorbed on the surface. The choice of an acid activated montmorillonite (KSF) was guided by some recent results concerning glyphosate adsorption: decreasing $\mathrm{pH}$ and increasing ionic strength lead to an increase of surface coverage and thus glyphosate adsorption (Damonte et al., 2006). These relatively large adsorption capacities may be suitable to evaluate the potential of MAS NMR to study the behaviour of glyphosate as sensitivity of NMR is rather low.

\section{Adsorption isotherms}

The adsorption isotherms were determined according to the OECD Guideline 106 (OECD, 2000) with a batch equilibrium method at $25^{\circ} \mathrm{C}$. Each experiment was repeated twice. The samples were dispersed in decarbonated deionized water $(10$ or $50 \mathrm{ml})$ in order to obtain a homogeneous dispersion and stirred for 24 hours before the pollutant was added. In the case of LDHs, the $\mathrm{pH}$ was adjusted to 7.5 by $\mathrm{HCl}$ $\left(0.1 \mathrm{~mol} \mathrm{litre}^{-1}\right)$ or $\mathrm{NaOH}\left(0.1 \mathrm{~mol}\right.$ litre $\left.^{-1}\right)$. Montmorillonite $\mathrm{KSF}$ buffered the medium to $\mathrm{pH} 4$ (no change during sorption process): thus no $\mathrm{pH}$ adjustment was necessary. After a contact time of 24 hours, the suspensions were centrifuged $(10$ minutes, $12500 \mathrm{~g})$. In the case of MCPA, some adsorption isotherms were carried out in fully (99\%) deuterated water to minimize contributions of clay protons during ${ }^{1} \mathrm{H}$ MAS NMR experiments. Solid-liquid ratios were: $100 \mathrm{mg}$ in $10 \mathrm{ml}(1 / 100)$ and $50 \mathrm{mg}$ in $10 \mathrm{ml}$ $(1 / 200)$ for glyphosate; $50 \mathrm{mg}$ in $50 \mathrm{ml}(1 / 1000)$ for MCPA; $50 \mathrm{mg}$ in $50 \mathrm{ml}(1 / 1000)$ and $500 \mathrm{mg}$ in $10 \mathrm{ml}(1 / 20)$ for $\mathrm{BTSO}_{3}$. In the case of $\mathrm{BTSO}_{3}$, the adsorption isotherms were recorded at $\mathrm{pH} 8.0$ in a concentration range between 0.10 and $2.0 \mathrm{mmol}^{-1} \mathrm{itr}^{-1}$ for the two solid-liquid ratios. It should be noted that at this $\mathrm{pH}, \mathrm{BTSO}_{3}$ may be principally present in its sulphonate form.

The amount of pollutant adsorbed by clays (Cs) was determined from the difference between the initial (Ci) and final (or equilibrium) concentrations $(\mathrm{Ce})$ of the pollutant per gram of clay adsorbent: $C s=(C i-C e) \times \mathrm{V} / \mathrm{m}$ (Equation 1), where $\mathrm{V}$ (litre) is the volume of the mixture and $\mathrm{m}$ (gram) is the mass of clay. The adsorption isotherms were obtained by plotting the amount of pollutant adsorbed (Cs) versus the adsorbate concentration in the equilibrium solution $(\mathrm{Ce})$.

\section{Measurements of pollutant concentrations}


MCPA concentrations were determined by UV spectrophotometry by measuring the absorbance at $279 \mathrm{~nm}$ with a Perkin-Elmer Lambda 2S UV-Visible spectrometer (Courtaboeuf, France). Concentrations of $\mathrm{BTSO}_{3}$ were measured by reversed-phase HPLC with a Perkin Elmer Series 200 chromatograph (Column SPHERI-5 RP-18; $5 \mu \mathrm{m}, 250 \times 4.6 \mathrm{~mm}$ ) equipped with a DAD UV detector set at $298 \mathrm{~nm}$. The mobile phase was acetonitrile/water $(20 / 80 \mathrm{~V} / \mathrm{V})$; flow rate: $0.7 \mathrm{ml}$ minute ${ }^{-1}$. Glyphosate was detected after derivatization (Miles \& Moye, 1988) by reversed-phase HPLC (Column Nucleodur C18, $5 \mu \mathrm{M}$, $150 \times 4.6 \mathrm{~mm}$ ) on an Agilent 1100 chromatograph (Massy, France) equipped with a fluorescent detector ( $270 \mathrm{~nm}$ for excitation and $317 \mathrm{~nm}$ for emission). The mobile phase was a mixture of phosphate buffer (50 mmol litre $\mathrm{KH}_{2} \mathrm{PO}_{4}$; $\mathrm{pH}$ adjusted to 6.0 with 2 mol litre ${ }^{-1} \mathrm{KOH}$ ) and acetonitrile, 70/30 V/V; flow rate: $1 \mathrm{ml}$ minute $^{-1}$.

FTIR measurements. FTIR spectra of the adsorbed pollutant-clay samples were recorded with a Perkin Elmer 16 PC FT-IR spectrophotometer on pellets by pressing, under vacuum, uniformly prepared mixtures of $2 \mathrm{mg}$ of the solid investigated and $198 \mathrm{mg}$ of spectrometry grade $\mathrm{KBr}$. Pellets were measured immediately after pressing.

${ }^{1}$ H liquid state NMR measurements. ${ }^{1} \mathrm{H}$ liquid state NMR was performed at $25^{\circ} \mathrm{C}$ at $500 \mathrm{MHz}$ on an Avance 500 Bruker spectrometer (Bruker Biospin, Wissembourg, France) equipped with a tripleresonance $\left({ }^{1} \mathrm{H},{ }^{13} \mathrm{C},{ }^{15} \mathrm{~N}\right)$ inverse probe with 5 -mm diameter tubes containing $600 \mu \mathrm{l}$ of sample, with water being suppressed by a classical two phase-shifted pulse saturation sequence. Approximately 256 scans were collected $\left(90^{\circ}\right.$ pulse, $7.3 \mu \mathrm{s}$; saturation pulse, $3 \mathrm{~s}$; relaxation delay, $3 \mathrm{~s}$; acquisition time, $4.679 \mathrm{~s}$; 65536 data points). A 1-Hz exponential line-broadening filter was applied before Fourier transformation, and a baseline correction was performed on spectra before integration using Bruker software. Under these conditions, the limit of detection and quantification were within the range of $1-10 \mu \mathrm{mol}$ litre ${ }^{-1}$, respectively.

MAS NMR measurements. NMR spectra were performed on a Bruker Avance DSX-300 spectrometer or a Bruker Avance 500 spectrometer, both equipped with a double-bearing magic angle spinning (MAS) probehead. The samples were packed in 4-mm zirconia rotors fitted with Kel-F caps. For hydrated sample analysis (HR MAS), the volume was restricted to approximately $12 \mu 1$ in the centre of the rotor by means of a Teflon insert.

The high-resolution ${ }^{13} \mathrm{C}$ solid state spectra were performed at $75.46 \mathrm{MHz}$ at the magic angle with a spinning rate of $10 \mathrm{kHz}$ at ambient temperature. A ramped cross-polarization (RACP) sequence was used to enhance ${ }^{13} \mathrm{C}$ magnetization. Hartmann-Hahn cross-polarization from protons to carbon was carried out at a proton nutation frequency of $70 \mathrm{kHz}$ over a contact time of $1.5 \mathrm{~ms}$, chosen according to variable contact time experiments. A TPPM decoupling with ${ }^{1} \mathrm{H}$ nutation frequency of $70 \mathrm{kHz}$, pulse length of $6.0 \mu \mathrm{s}$ and phase shift of $15^{\circ}$ was used. A recycle delay of $4 \mathrm{~s}$ was used. Free induction decays (FID) were digitized into $6 \mathrm{~K}$ data points and Fourier-transformed after applying $5 \mathrm{~Hz}$ exponential line-broadening. The number of transients was fitted to reach optimal signal to noise ratios $(2000-4096)$. The ${ }^{13} \mathrm{C}$ chemical shifts were referenced to an external reference taken from the carbonyl group of glycine (176.03 p.p.m.).

${ }^{1}$ H MAS and ${ }^{1} \boldsymbol{H}$ MAS Hahn echo experiments. These were carried out at $300.13 \mathrm{MHz}$. The high resolution component of a ${ }^{1} \mathrm{H}$ MAS spectrum can be well isolated from the broadline one by the Hahn echo sequence with a long echo time. Compared with the CRAMPS experiment (Duer, 2002), which measures the proton system as a whole, the high resolution echo-MAS method measures only a fraction of the solid, which is usually small at room temperature and quite different from the majority of the solid in both molecular motion and chemical environment. However, when several resonances with different chemical shifts exist, a long delay time will cause severe first-order phase distortion. The phase distortion usually becomes increasingly severe with increase in the delay time and the magnetic field. The Hahn echo pulse sequence $(\pi / 2-\tau / 2-\pi-\tau / 2-\mathrm{AQ})$ is found to be very useful for obtaining a pure absorption mode high resolution spectrum at both high field and longer delay times. In addition, a greater sensitivity is obtained by the echo sequence because the main field inhomogeneity is refocused. We have chosen to use a rotor synchronized version of this classical Hahn echo experiment in order to improve the efficiency of the refocalization. When $\tau$ is larger than $1 \mathrm{~ms}$, a perfectly phased high resolution spectrum is obtained. As 
for all spin echo experiments, the high resolution spectrum obtained by the echo-MAS experiment at an arbitrary $\tau$ value is generally not quantitative. Thus the choice of the echo value is a crucial issue. The spinning rate was $12 \mathrm{kHz}$ for these experiments. A $\pi / 2$ pulse of $3.9 \mu$ s was used. A variety of echo times was evaluated $(100 \mu \mathrm{s}-1.6 \mathrm{~ms})$. A $3 \mathrm{~Hz}$ exponential line-broadening was applied before Fourier transformation. The same phase and baseline corrections were applied to all spectra. The chemical shifts were referenced to $\mathrm{TSPd}_{4}$ taken as an external reference.

${ }^{1}$ H HR-MAS experiments. To assess the mobility of adsorbed pollutants on clays, samples (15 mg) were swollen with $30 \mu \mathrm{l}$ of deionised water. The sample volume was restricted to approximately $12 \mu \mathrm{l}$ in the centre of the rotor by means of a Teflon insert. The spectra were recorded with a rotor-synchronized single pulse experiment $\left(\mathrm{t} 90^{\circ}=6.2 \mu \mathrm{s}\right)$ with pre-saturation during the relaxation delay $(3 \mathrm{~s})$ for water resonance suppression. Its robustness was greater than that of the classical Watergate experiment in such heterogeneous samples. The samples were spun $\left(v_{\mathrm{r}}\right)$ at $3 \mathrm{kHz}$. Chemical shifts are reported in p.p.m. relative to $\mathrm{TSPd}_{4}$ as external standard. $\mathrm{TSPd}_{4}$ was also used for quantification. The number of transients was typically 128 or 256 to achieve a good signal-to-noise ratio.

${ }^{1} \mathrm{H} \mathrm{T}_{1}$ measurements of $\mathrm{BTSO}_{3}$ were carried out using the inversion-recovery sequence that included two water saturation periods during recycle and recovery delays. The measurements were repeated twice both on a pure $\mathrm{BTSO}_{3}$ solution and on $\mathrm{LDH}-\mathrm{BTSO}_{3}$ complexes.

$\mathrm{BTSO}_{3}$ biodegradation in the presence of clays. Rhodococcus erythropolis was grown and prepared as

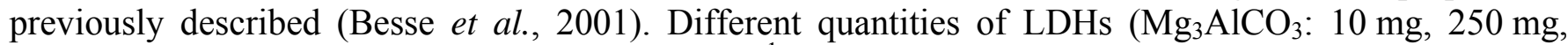
$500 \mathrm{mg}, 1 \mathrm{~g}$ ) were added to $8 \mathrm{ml}$ of a $2 \mathrm{mmol}$ litre ${ }^{-1} \mathrm{BTSO}_{3}$ solution in deionised water containing or not an internal standard (DSS at $0.5 \mathrm{mmol}$ litre $^{-1}$ ). The suspension was incubated in $50 \mathrm{ml}$ Erlenmeyer flasks at $27^{\circ} \mathrm{C}$, with shaking at 200 r.p.m. After 24 hours, a cell suspension $(0.2 \mathrm{~g}$ wet weight biomass prepared as previously described (Haroune, 2003)) in $2 \mathrm{ml} \mathrm{Volvic}{ }^{\circledR}$ (Danone, Volvic, France) water was added. This mineral water was chosen for its low and constant ion content (especially carbonates that can drastically affect adsorption properties). Incubation conditions were the same as those described previously $\left(27^{\circ} \mathrm{C}\right.$, with shaking at 200 r.p.m). Samples $(500 \mu \mathrm{l})$ were taken regularly to be analysed by HPLC and ${ }^{1} \mathrm{H}$ liquid state NMR after centrifugation (12 $500 \mathrm{~g}, 10$ minutes). Concomitantly, $12 \mu \mathrm{l}$ samples of the suspension (without centrifugation) were taken and introduced into a 4-mm zirconia rotor to be directly analysed by ${ }^{1} \mathrm{H}$ HR-MAS NMR (without any treatment). Controls without cells were prepared under the same conditions. Controls were also prepared to evaluate the impact of DSS on $\mathrm{BTSO}_{3}$ metabolism.

\section{Results and discussion}

\section{Adsorption and properties of glyphosate adsorbed on montmorillonite KSF}

Two solid-liquid ratios were used (1/100 and 1/200) and gave similar results. Isotherms of glyphosate (PMG) adsorption on this montmorillonite are all non-linear, have two steps and indicate that ligand exchange is the main adsorption mechanism (Figure 2).

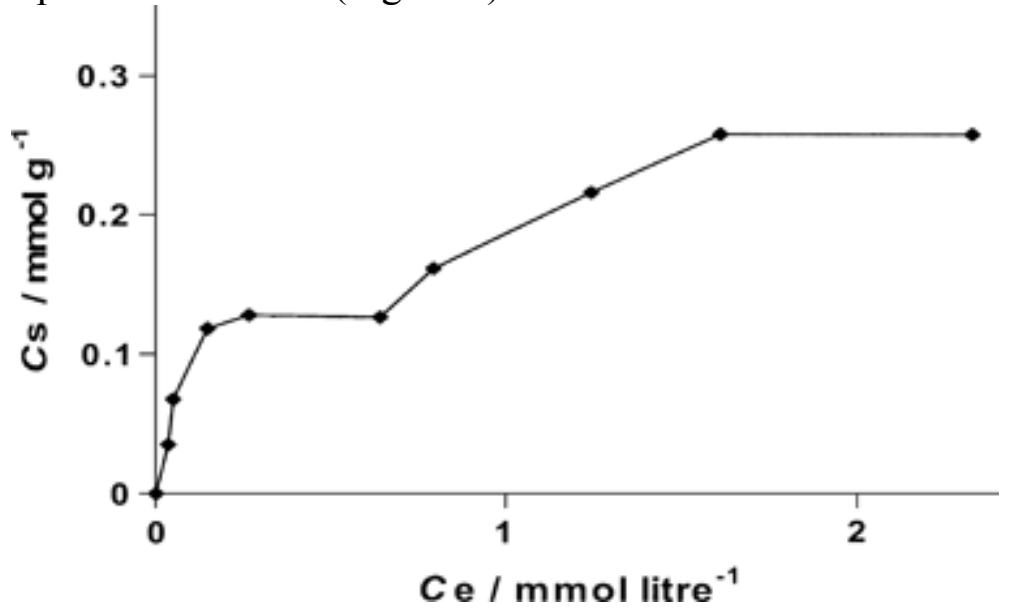

Figure 2 Isotherm of glyphosate adsorption on montmorillonite KSF for a 1/200 solid-liquid ratio.

$\mathrm{X}$-ray diffractograms were made for material representing each point of the isotherm and indicated an increase in the basal spacing from 11.8 to $13.2 \AA$. This increase in the interlamellar distance appears 
insufficient for guest PMG between the sheets. It is clear that glyphosate may interact with a positively charged surface through its ammonium moiety. However, to be intercalated into the sheets, PMG must be oriented parallel to the layers and the minimum distance for this was calculated to be $4 \AA$. No other significant structural changes were observed after adsorption.

The FTIR spectra of pure and exchanged montmorillonites were similar (data not shown). The content of physisorbed water was greater after adsorption of PMG. Vibrational bands of PMG were systematically masked by those of the clays. Consequently, FTIR spectroscopy is not an appropriate method in this case. Thus, we recorded ${ }^{1} \mathrm{H}$ MAS Hahn echo spectra with a $1 \mathrm{~ms}$ echo time (data not shown). However, mobile water resonance dominated the spectra, avoiding unambiguous data analysis. The same samples were subsequently hydrated $(200 \% \mathrm{w} / \mathrm{w})$ and analysed by ${ }^{1} \mathrm{H}$ 1D HR-MAS NMR. The primary aim was to mimic environmental conditions more reasonably, in which water content usually plays an important role in the fate of pollutants. Moreover, it thus may be possible to increase the mobility of the adsorbed PMG. By this means, we expected sharper signals. The ${ }^{1}$ H HR-MAS spectra of hydrated samples are presented in Figure 3(b-d). Resonances in the range 2.1-2.3 p.p.m. belong to 'impurities' of montmorillonite 'salted out' during adsorption of PMG. These resonances were not present in the PMG solution and they were not observed when montmorillonite was analysed just after swelling (Figure 3a). The major features of these spectra were as follows. (i) The high resolution of the spectra containing PMG, with its resonances clearly observed at 3.24 and 3.82 p.p.m., the ${ }^{2} J_{{ }^{1} H-{ }^{31} P}$ coupling constant $(11.5 \mathrm{~Hz})$ being observed on some spectra. (ii) PMG signal intensities increased with the amount of PMG loaded onto the surface. It indicates that NMR preserves its quantitative properties despite the heterogeneous state of the samples. (iii) Signals were rather sharp, suggesting a relatively weak interaction between PMG and the negatively charged surface. This hypothesis is reasonable bearing in mind that PMG must interact with the montmorillonite surface by its ammonium moiety, contrary to previously published studies on goethite in which PMG entered the coordination sphere of iron via one of its phosphonate oxygens (Sheals et al., 2002). Further experiments are in progress in our group to confirm the nature of the interaction of PMG with the surface of this montmorillonite.

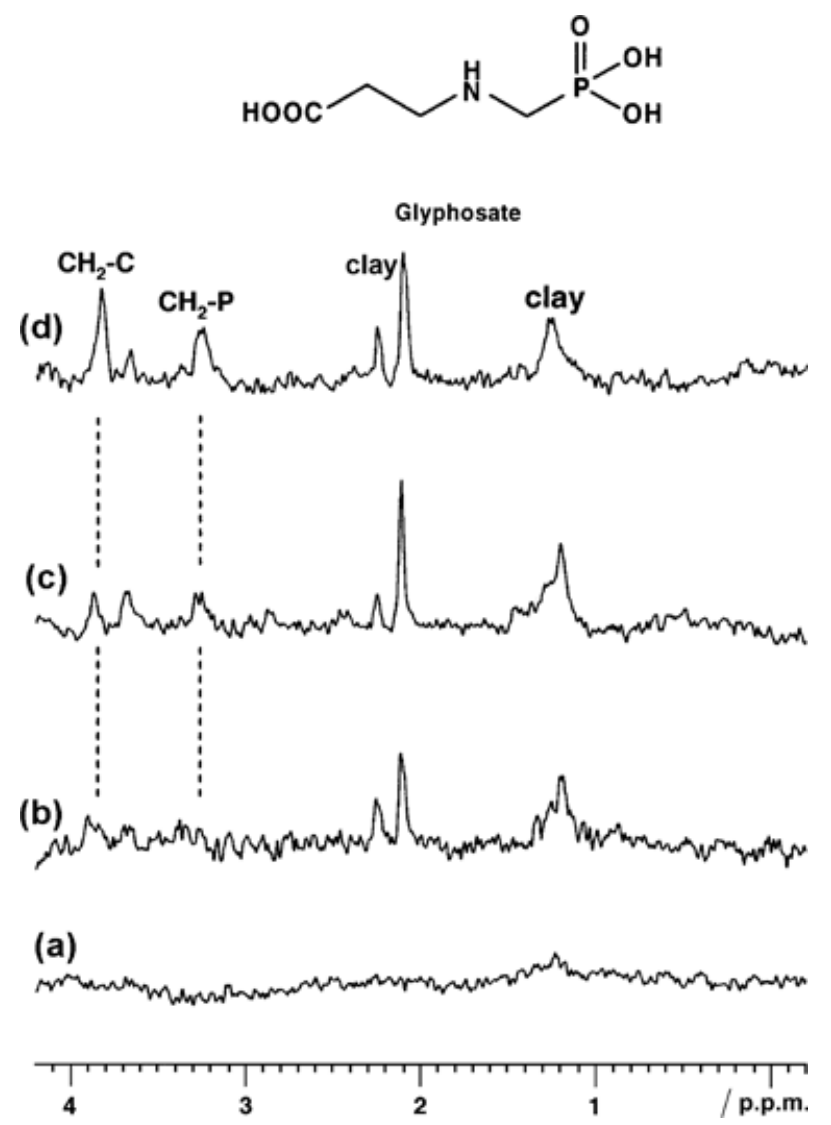

Figure $3{ }^{1}$ H HR-MAS spectra of hydrated (200\% w/w) PMG-montmorillonite phases obtained after PMG adsorption for a $1 / 200$ solid-liquid ratio (spinning rate: $3 \mathrm{kHz}$ ). From bottom to top: $C \mathrm{~s}=0,0.12,0.16$ and $0.29 \mathrm{mmol} \mathrm{g}^{-1}$. Note that (a) corresponds to the spectrum of the hydrated montmorillonite. 
Thus, to increase our knowledge of the mechanisms involved at the solid-liquid interface, we decided to simplify the solid model.

\section{MCPA adsorption}

To evaluate the potential of MAS NMR to study interactions between MCPA and fully characterized hydrotalcite-like materials (LDHs), adsorption isotherms were determined in water or deuterated water. The shape of the isotherms makes it difficult to classify them. The isotherms resemble S-type isotherms but tend to L-type for Ce $1.5 \mathrm{mmol}$ litre ${ }^{-1}$. The changes from $\mathrm{S}$ to $\mathrm{L}$ types within the same isotherm are likely to be due to changes from external to interlayer adsorption. Indeed, at a $C e$ value of $1.3 \mathrm{mmol}$ litre $^{-1}$, intercalation proceeds via an increase of the basal spacing from $7.94 \AA$ for $\left[\mathrm{Mg}_{3} \mathrm{AlCl}\right]$ to $22.1 \AA$ for $\left[\mathrm{Mg}_{3} \mathrm{AlMCPA}\right]$ as shown by powder X-ray diffraction. We have previously shown that ${ }^{13} \mathrm{C} \mathrm{CP}$ MAS spectra recorded on dry samples clearly showed the presence of adsorbed and intercalated MCPA in the clay samples (Combourieu et al., 2001). The various carbons of the MCPA molecule did not shift compared with free MCPA. A slight difference of relative $\mathrm{CO}_{3}{ }^{2-}$ and $\mathrm{C}_{1}$ signal intensities for the two populations (adsorbed and intercalated) was due to the poorer efficiency of the polarization transfer between ${ }^{1} \mathrm{H}$ and ${ }^{13} \mathrm{C}$ nuclei located at the surface. Improved resolution of the intercalated MCPA spectrum can be explained by greater structural order of this solid phase. Solid state ${ }^{1} \mathrm{H}$ MAS experiments made on both adsorbed and intercalated clays showed very broad signals and did not allow differentiation of both populations of MCPA. This is easily explained by the presence of a large number of protons in LDHs, mainly from hydroxides, structural and physisorbed water. To solve this problem, adsorption isotherms were obtained in deuterated water. The ${ }^{1} \mathrm{H}$ MAS spectrum corresponding to Ce $\left(1 \mathrm{mmol}\right.$ litre $\left.{ }^{-1}\right)$ is shown in Figure 4(d) and was compared with that of intercalated MCPA (Figure 4c). Greater resolution of the spectra was possible but adsorbed and intercalated samples could not be differentiated by this means.

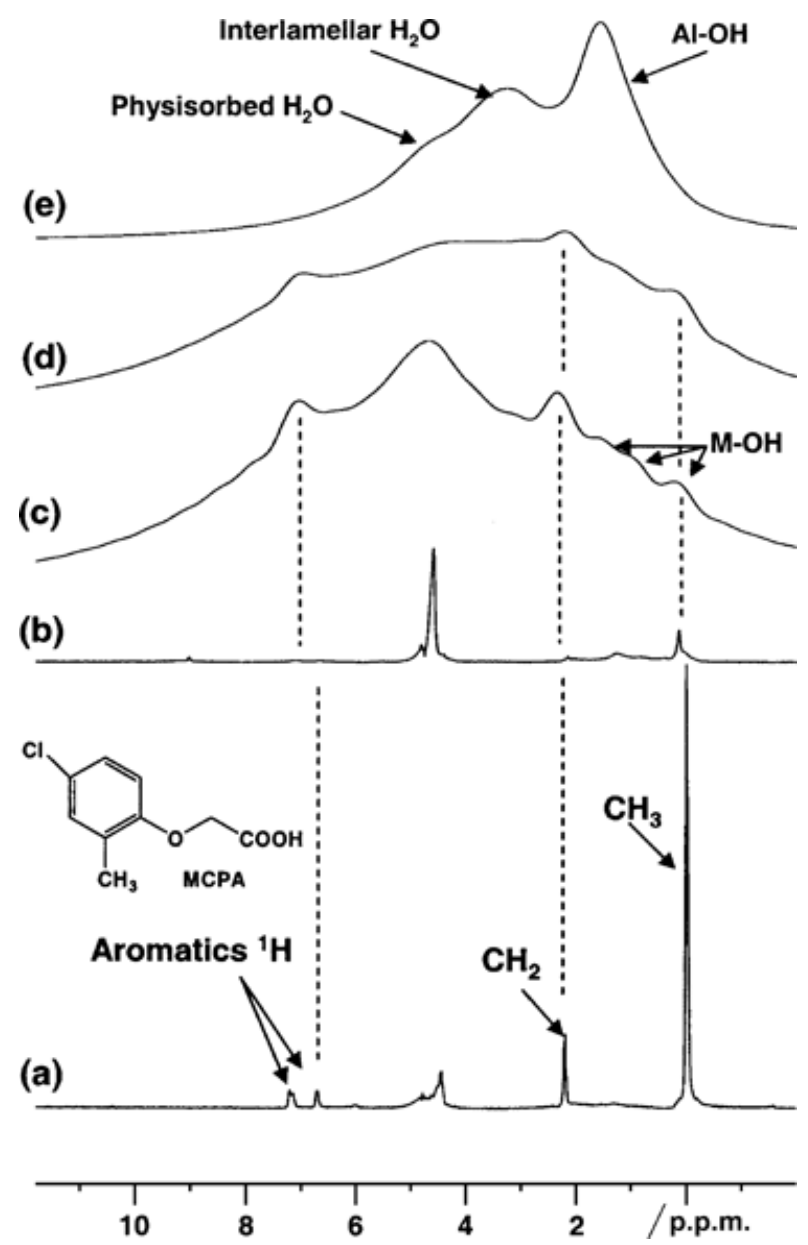

Figure $4{ }^{1} \mathrm{H}$ MAS spectra of hydrated samples obtained during the adsorption (a), the intercalation (b) of MCPA on the $\mathrm{Mg}_{3} \mathrm{AlCl}$ phase. The exchanges were carried out in $\mathrm{D}_{2} \mathrm{O} .{ }^{1} \mathrm{H}$ MAS spectra of dry samples: (c) intercalated, (d) adsorbed and (e) precursor material. 
The next step was to hydrate the samples strongly and to record the ${ }^{1} \mathrm{H}$ HR-MAS NMR spectrum at a slow spinning rate $(<6 \mathrm{kHz})$. As mentioned above, in HR-MAS NMR, the signals detected basically reflect the degree of mobility of the species loaded onto the surface of a solid matrix: very mobile molecules give narrow signals, close to those of liquid-state NMR spectra. In contrast, when the strength of the interaction increases, the signals are broader. In this way, despite the massive presence of water in the samples, we were able to differentiate adsorbed versus intercalated MCPA (Combourieu et al., 2001). The adsorbed species gave sharp signals, close to those of liquid state ${ }^{1} \mathrm{H}$ NMR $\left({ }^{3} J_{{ }^{1} H-{ }^{1} H}\right.$ coupling constants are visible), indicating great mobility at the solid-aqueous interface. In contrast, the intercalated species gave very wide, unresolved resonances due to their strong interactions with the clay. Thus, it appears that HR-MAS NMR performed on greatly hydrated samples was suitable to discriminate different species (mobile and immobile) of a pesticide loaded onto the surface of anionic clays.

In order to generalize this simple approach to other pollutants and materials, we have investigated the behaviour of another organic pollutant on LDHs.

\section{Behaviour of 2-benzothiazole sulphonate loaded on anionic clays}

BTSO $_{3}$ adsorption. The adsorption on the chloride phase was stronger for the $1 / 1000$ solid-liquid ratio (Figure 5). It may be due to a more favourable dispersion effect. The $\mathrm{BTSO}_{3}$ adsorption on the carbonate phase (1/1000 ratio) was less strong than for the chloride one (Figure 5a). This result, enhanced for $\mathrm{Ce}<1 \mathrm{mmol}$ litre $^{-1}$, is explained by the strong affinity of carbonate ions for the positively charged LDH surface. Indeed, for $\mathrm{Ce}<1 \mathrm{mmol}$ litre ${ }^{-1}$ competition by carbonate affected $\mathrm{BTSO}_{3}$ adsorption at the surface. With a $1 / 20$ solid-liquid ratio, no significant $\mathrm{BTSO}_{3}$ adsorption was observed for this carbonatecontaining phase (data not shown) while little adsorption occurs for the chloride phase (Figure 5b), with Cs values roughly 100 times less than for the 1/1000 solid-liquid ratio.
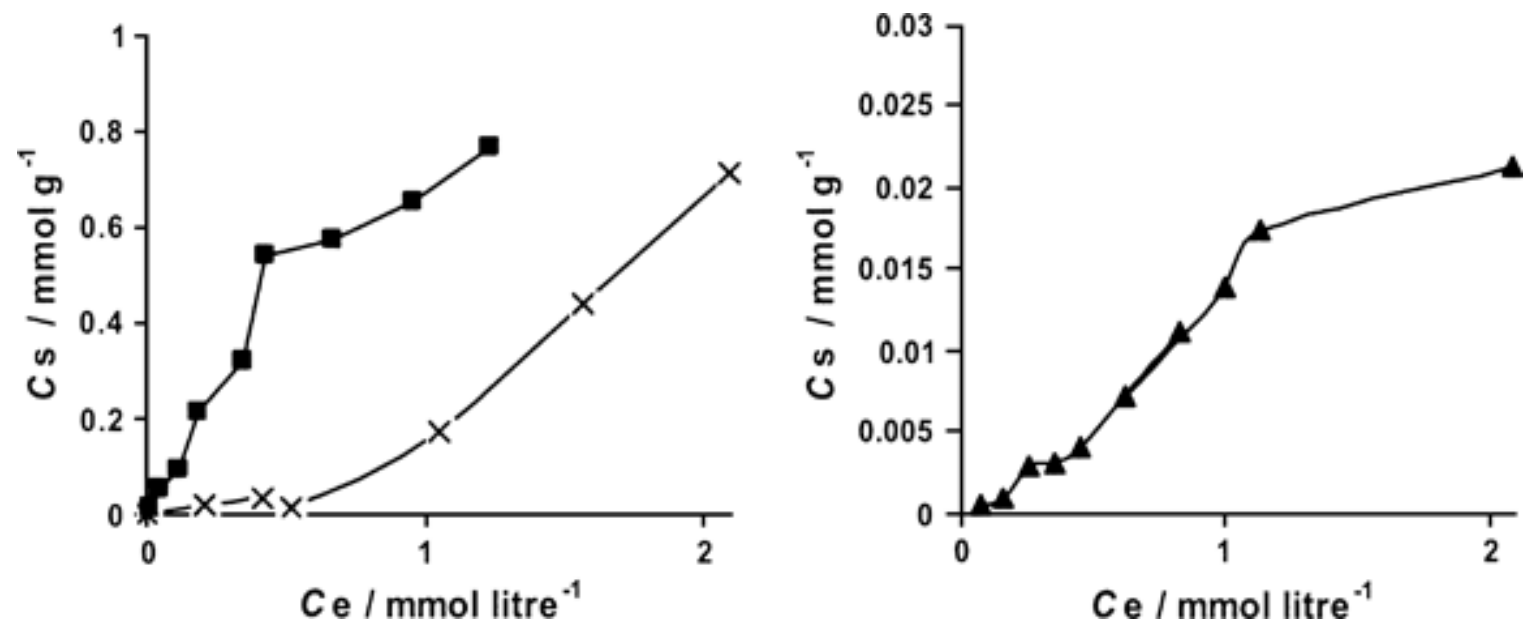

Figure 5 Isotherms of $\mathrm{BTSO}_{3}$ adsorption (a) on $\mathrm{Mg}_{3} \mathrm{AlCO}_{3}(\times)$ and on $\mathrm{Mg}_{3} \mathrm{AlCl}$ for a $1 / 1000$ solid-liquid ratio (*) and (b) on $\mathrm{Mg}_{3} \mathrm{AlCl}$ for $1 / 20$ solid-liquid ratio ( $\mathbf{\wedge}$ ).

For the various phases, the different solid-liquid ratios and for each point of the isotherms, dry samples were analysed by X-ray diffraction, FTIR and MAS NMR spectroscopy. However, to simplify the following discussion, only results concerning the chloride phase are presented because conclusions are similar for all phases.

For a $1 / 20$ solid-liquid ratio, the XRD patterns did not reveal any modification of mineral structures compared with the precursor phase, whatever the initial concentration of $\mathrm{BTSO}_{3}$. However, for a 1/1000 solid-liquid ratio, new diffraction peaks appeared at $2 \mathrm{c} / 3\left(\mathrm{c}=2 \mathrm{mmol}\right.$ litre $\left.^{-1}\right)$ (Figure 6). Intercalation of $\mathrm{BTSO}_{3}$ anions in the lamellar host structure was clearly demonstrated by the increase in the basal spacing, from $7.68 \AA$ for the chloride precursor to $18.2 \AA$ for the organic intercalate (Figure 6 ). This distance suggests that the sulphonate moiety interacts directly with the positively charged mineral surface, the benzene ring being perpendicular to the layers. No intermediate distance was observed on spectra below 
concentrations of $2 \mathrm{c} / 3$, indicating that the adsorption - intercalation process was an anion exchange mechanism.

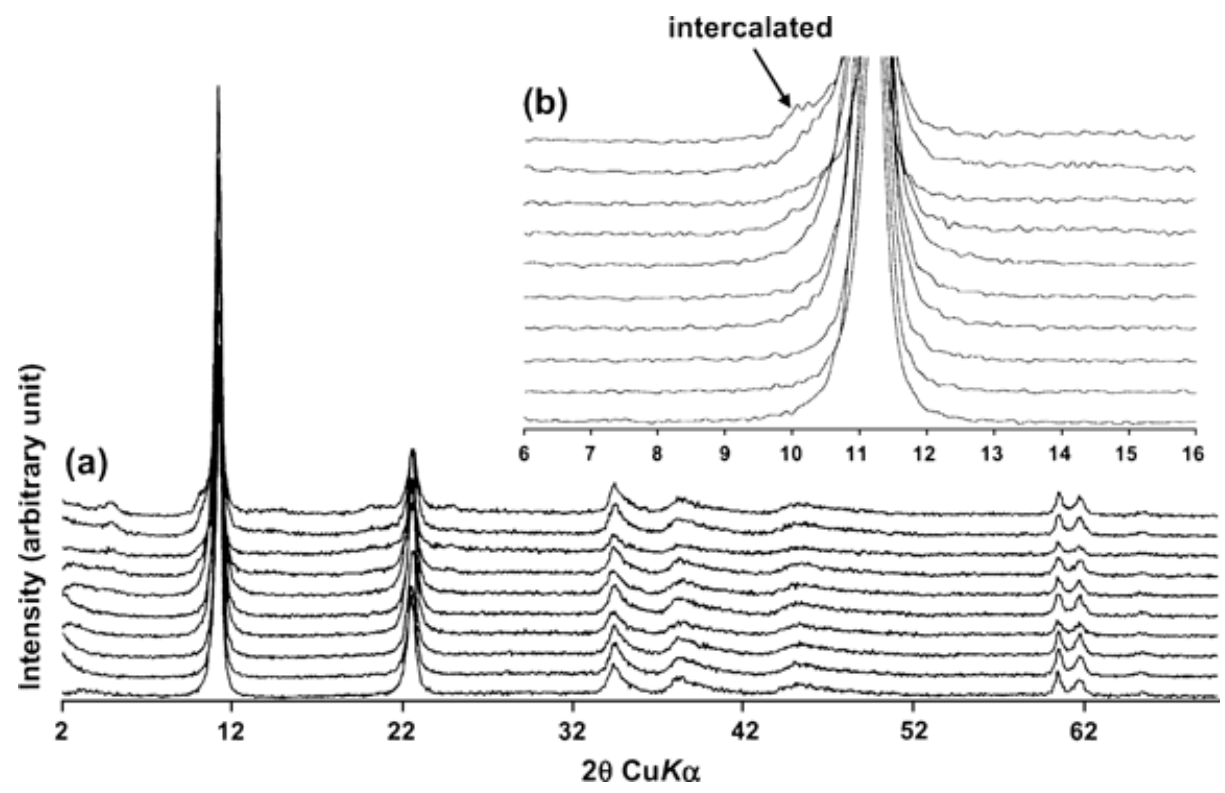

Figure 6 (a) X-ray diffraction patterns recorded after adsorption of $\mathrm{BTSO}_{3}$ on $\mathrm{Mg}_{3} \mathrm{AlCl}$ material for a 1/1000 solidliquid ratio. From top to bottom: $\mathrm{c}\left(2 \mathrm{mmol}\right.$ litre $\left.^{-1}\right), 3 \mathrm{c} / 4,2 \mathrm{c} / 3, \mathrm{c} / 2, \mathrm{c} / 3, \mathrm{c} / 4, \mathrm{c} / 5, \mathrm{c} / 10, \mathrm{c} / 20$, blank. (b) Expanded region.

FTIR spectra of the $\mathrm{Mg}_{3}-\mathrm{Al}-\mathrm{Cl}$ precursor and the $\mathrm{BTSO}_{3}$ exchanged samples in a solid-liquid ratio of $1 / 20$ were identical. No vibrational band of $\mathrm{BTSO}_{3}$ was visible, although the adsorption isotherm clearly indicated an adsorption process (Figure 7). For a 1/1000 solid-liquid ratio, vibration modes of $\mathrm{BTSO}_{3}$ were visible from concentrations of $\mathrm{c}$ to $\mathrm{c} / 4$ but not below. The $\mathrm{S}=\mathrm{O}$ band was shifted from 1250 to $1222 \mathrm{~cm}^{-1}$ after exchange, suggesting greater covalent character. The $\mathrm{C}=\mathrm{N}$ band $\left(1260 \mathrm{~cm}^{-1}\right)$ was unaffected by adsorption and/or intercalation during exchange. This result confirmed that $\mathrm{BTSO}_{3}$ interacts with the surface by its sulphonate moiety. However, the spectra did not show any change between adsorbed and intercalated samples. This result indicates a similar interaction between the pollutant and clays during adsorption and intercalation, with $\mathrm{BTSO}_{3}$ being perpendicular to the sheets.
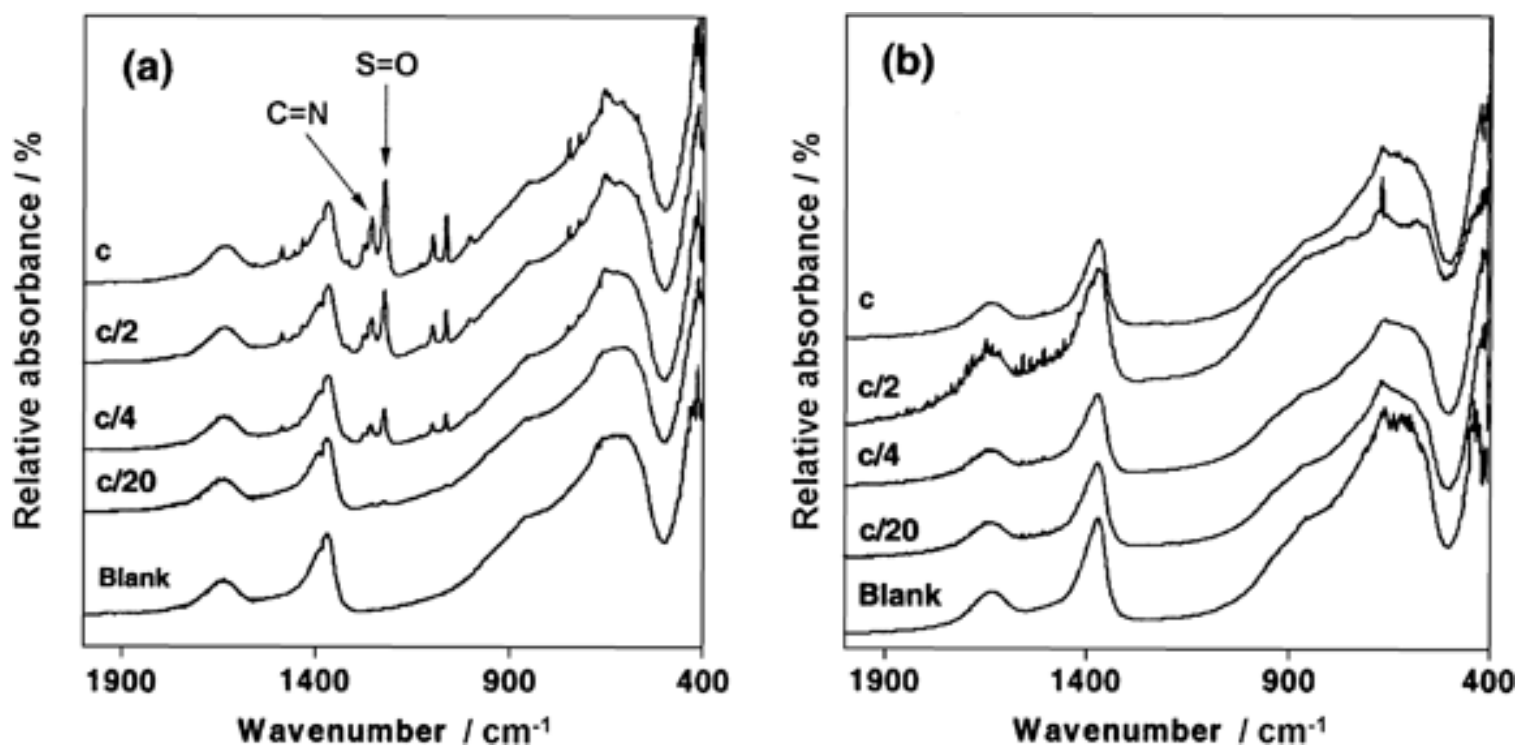

Figure 7 FTIR spectra of $\mathrm{Mg}_{3} \mathrm{AlCl}$ after adsorption of $\mathrm{BTSO}_{3}$; (a) $1 / 1000$ and (b) 1/20 solid-liquid ratios.

\section{MAS NMR}

To compare FTIR spectra recorded on dry samples with NMR data, CPMAS ${ }^{13} \mathrm{C}$ experiments were performed on dry samples (Figure 8). Resonances between 119 and 130 p.p.m. correspond to carbons C4, C5, C6 and C7 (see Figure 8 for carbon numbering). The apparent loss of a resonance in Figure 8(b) is due to a small variation in chemical shift consequent on a $\pi$ - $\pi$ stacking effect between two $\mathrm{BTSO}_{3}$ 
aromatic rings. Moreover, the poorer resolution - probably due to a greater disorder at the surface after adsorption of $\mathrm{BTSO}_{3}$ - does not allow observation of all resonances. Small variations in carbons C3a and $\mathrm{C} 7 \mathrm{a}{ }^{13} \mathrm{C}$ chemical shifts and in the shape of signals were observed between pure and adsorbed and/or intercalated $\mathrm{BTSO}_{3}$ samples. The $\mathrm{C} 2$ resonance was also shifted by 3 p.p.m., which suggests the involvement of the sulphonate group in the interaction with clays. However, these slight changes do not allow us to determine a particular geometry for the pollutant. The same effect as that described for MCPA was observed for intensities. Quantities of $\mathrm{BTSO}_{3}$ loaded in intercalated samples were about 10 times greater than those present in adsorbed samples. Consequently, the source of protons was bigger and the polarization transfer more efficient for intercalated samples. Therefore, CPMAS ${ }^{13} \mathrm{C}$ NMR did not provide new information on the kind of interactions involved. Nevertheless, it should be noted that both $1 / 20$ and 1/1000 solid-liquid ratios gave identical results for intercalated versus adsorbed samples.

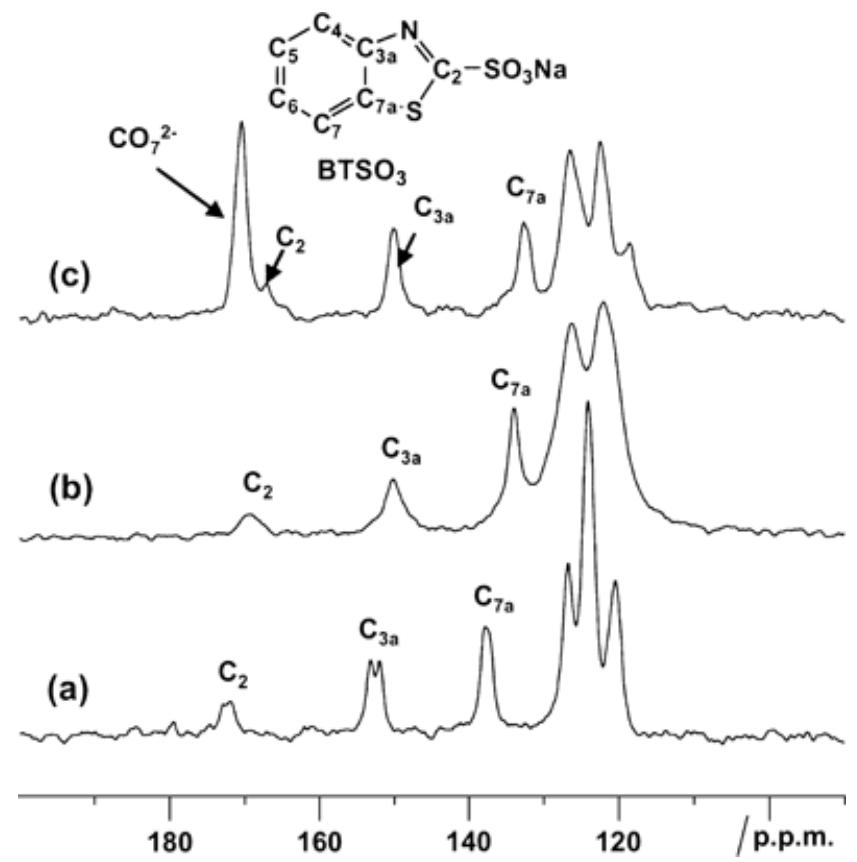

Figure 8 CPMAS ${ }^{13} \mathrm{C}$ NMR spectra of (a) pure, (b) adsorbed and (c) intercalated (co-precipitated) $\mathrm{BTSO}_{3}$ on the $\mathrm{Mg}_{3} \mathrm{AlCl}$ phase. Spinning rate: $12 \mathrm{kHz}$.

To obtain more information from NMR data, ${ }^{1} \mathrm{H}$ Hahn echo experiments were carried out on dry samples (Figure 9).
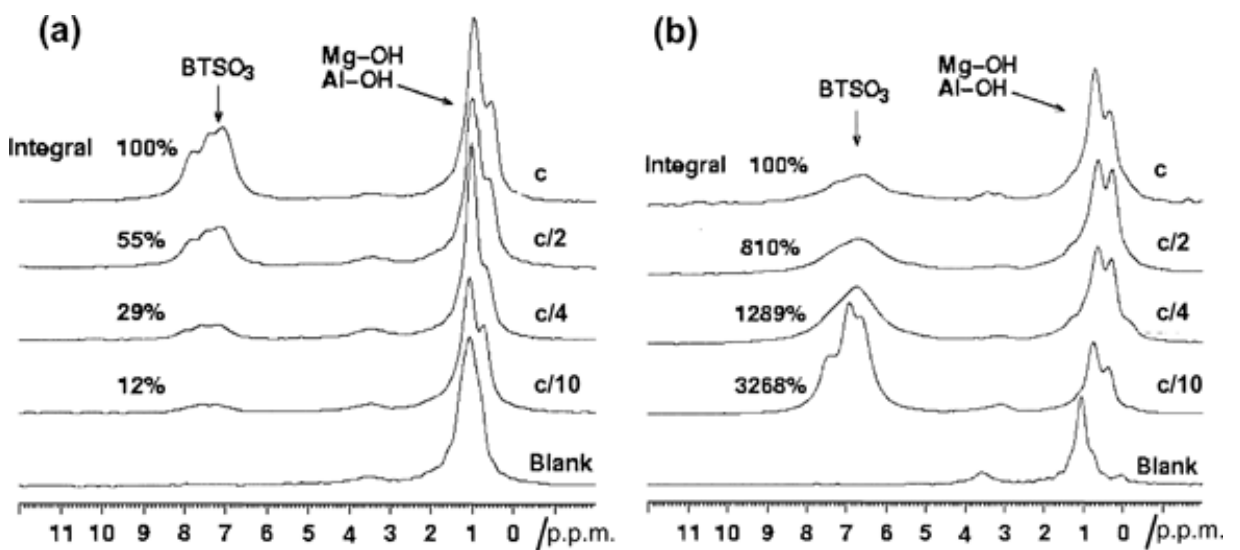

Figure $9{ }^{1} \mathrm{H}$ MAS Hahn echo spectra of the $\mathrm{BTSO}_{3}-\mathrm{Mg}_{3} \mathrm{AlCl}$ phase obtained (a) for $1 / 20$ and (b) 1/1000 solid-liquid ratios. The percentages correspond to signal area normalized to the greatest concentration used in the adsorption isotherms. Blank: spectra of precursor, without $\mathrm{BTSO}_{3}$.

Hahn echo experiments were carried out for the two solid-liquid ratios and each point of the isotherms was analysed by this sequence. Varying echo times provided useful results. At an echo time of $410 \mu \mathrm{s}$, the residual of the broadline component was still visible (data not shown). For an echo time of $825 \mu$ s, the spectrum was dominated by the high-resolution component and the intensity of the broadline component 
was greatly reduced. Quantification was then possible. Above $900 \mu \mathrm{s}$, most of the high-resolution component was lost. For the $1 / 20$ solid-liquid ratio, ${ }^{1} \mathrm{H}$ Hahn echo spectra showed that signal intensities increased with the quantity of $\mathrm{BTSO}_{3}$ adsorbed onto the surface. Conversely, the ${ }^{1} \mathrm{H}$ NMR signals decreased for the 1/1000 solid-liquid ratio while the amount of $\mathrm{BTSO}_{3}$ loaded onto the material increased. These results were complementary to the FTIR and X-ray diffraction pattern data. They may be explained thoroughly because a complete mathematical development exists for the Hahn echo experiment (Bilski et al., 2002). It has been established for the two types of solid echo experiments $(\pi / 2-\tau / 2-\pi-\tau / 2-A Q$ and $\pi / 2-$ $\tau / 2-\pi / 2-\tau / 2-\mathrm{AQ})$ that time position and amplitude of the solid-echo maximum depend on the correlation time, $\tau_{c}$, of molecular motion, and on the width of the RF pulses. When the pollutant is constrained near the surface or intercalated into the lamellar host, a slow-motion region may be reached. Consequently, the amplitude of the echo signal is reduced and its maximum is shifted to the end of the second pulse. It thus appears that the signal intensity in a Hahn echo experiment can be used to appreciate the global 'molecular dynamic process' or more generally the 'macroscopic mobility' of an organic pollutant loaded onto the surface of a solid matrix. Thus, the use of such a NMR experiment may be appropriate only when there is little adsorption, which is the dominant situation in the environment.

\section{H HR-MAS 1D experiments}

Further experiments were carried out on greatly hydrated $(200 \% \mathrm{w} / \mathrm{w})$ samples in order to appreciate the various degrees of mobility of the pollutant. The $\mathrm{BTSO}_{3}$ signals were well resolved. For the 1/1000 solidliquid ratio, $\mathrm{BTSO}_{3}$ concentrations found in heterogeneous media by HR-MAS and in solution by liquidstate NMR were similar. This indicates that under these conditions HR-MAS only reflects the fraction of the pollutant with a great mobility; that is, interacting weakly with the surface. Thus, the small fraction of $\mathrm{BTSO}_{3}$ strongly adsorbed onto clays (as shown by adsorption isotherms) cannot be observed by HRMAS, contrary to ${ }^{1} \mathrm{H}$ MAS NMR performed on dry samples with high-power amplifiers. This result is consistent with that found for MCPA. For the ratio $1 / 20$, the same results were observed. The sole limitation is the relatively high detection threshold of HR-MAS (measured at $30 \mu \mathrm{M}$ in our conditions) because adsorbed quantities are less in this case (Figure 5).

Then, we estimated the strength of the interaction in the case of weak adsorption via longitudinal relaxation times $\left(\mathrm{T}_{1}\right)$ of both $\mathrm{BTSO}_{3}$ and the internal standard $\left(\mathrm{TSPd}_{4}\right)$.

\section{Longitudinal relaxation time $\left(\mathrm{T}_{1}\right)$ measurements by ${ }^{1} \mathrm{H}$ HR-MAS}

An inversion-recovery sequence including water saturation during recycle and recovery delays was used. In the presence of clays, a decrease of $\mathrm{T}_{1}$ was observed for all signals (Table 1), thus indicating a priori less mobility of organic compounds. This may be due to weak interaction with the surface and is consistent with results previously described.

Table $1{ }^{1} \mathrm{H}$ Longitudinal relaxation of $\mathrm{BTSO}_{3}$ signals and $\mathrm{TSPd}_{4}$ measured directly by HR-MAS in the presence or the absence of clays

\begin{tabular}{|c|c|c|c|c|}
\cline { 2 - 5 } \multicolumn{1}{c|}{} & \multicolumn{2}{c|}{ TSPd $_{4}$} & \multicolumn{2}{c|}{ BTSO $_{3}$} \\
\cline { 2 - 5 } \multicolumn{1}{c|}{} & 0 p.p.m. & $\mathbf{7 . 6 4}$ p.p.m. & $\mathbf{7 . 7 0}$ p.p.m. & 8.14 p.p.m. \\
\hline Without clays & 3.511 & 4.409 & 4.278 & 5.660 \\
\hline With clays & 2.948 & 3.695 & 3.171 & 4.646 \\
\hline
\end{tabular}

\section{$\mathrm{BTSO}_{3}$ metabolism in the presence of clays}

We have recently established the full metabolic pathway of BTs, including $\mathrm{BTSO}_{3}$, by Rhodococcus erythropolis in homogenous suspension (without clays) on a laboratory scale (Haroune, 2003). In the presence of clays, the degradation rate of $\mathrm{BTSO}_{3}$ decreased substantially due to the poorer bioavailability of the pollutant. The potential of ${ }^{1} \mathrm{H}$ HR-MAS NMR spectroscopy to study this biodegradation in the presence of clay was tested. Our aim was to check whether the fraction of the pollutant interacting with clays (as suggested by the $\mathrm{T}_{1}$ data) was less bioavailable than that 'free' in the medium.

The kinetics of degradation obtained by ${ }^{1} \mathrm{H}$ HR-MAS (without centrifugation) were compared with those analysed by HPLC and liquid state ${ }^{1} \mathrm{H}$ NMR after centrifugation. In this case, DSS was chosen as the internal standard. Indeed, it is not transformed either chemically or biochemically in the presence of clays, contrary to $\mathrm{TSPd}_{4}$. Moreover, it is not significantly adsorbed onto LDHs. Finally, DSS does not affect the bacterial metabolism of $\mathrm{BTSO}_{3}$. 
The ${ }^{1} \mathrm{H}$ HR-MAS spectra of these complex and heterogeneous mixtures are presented in Figure 10. Note that despite the presence of cells and clay particles, spectra were of good quality, with $\mathrm{BTSO}_{3}$ signals sharp and well resolved. This sharpness suggests a great mobility of the pollutant. The analyses of supernatants after centrifugation (12 $500 \mathrm{~g}, 10$ minutes) showed that with $10 \mathrm{mg}$ of LDHs, no difference was observed compared with controls without clays (data not shown). From $250 \mathrm{mg}$ to $1 \mathrm{~g}$ of LDHs, the degradation rate decreased slightly but not significantly. The $\mathrm{pH}$, increasing from 8.3 to 8.9 with the amount of hydrotalcite (from $10 \mathrm{mg}$ to $1 \mathrm{~g}$ ), was not responsible for this slight decrease. Controls without clay particles but with various ions introduced in the medium (as $\mathrm{HCl}, \mathrm{MgCl}_{2}$ or $\mathrm{MgCO}_{3}, \mathrm{NaCl}$ or $\mathrm{NaOH}$ ) revealed that they were responsible for this decrease (inhibition of some metabolic pathways). Nevertheless, no metabolites of $\mathrm{BTSO}_{3}$ were observed in either case, $\mathrm{BTSO}_{3}$ being partially mineralized.

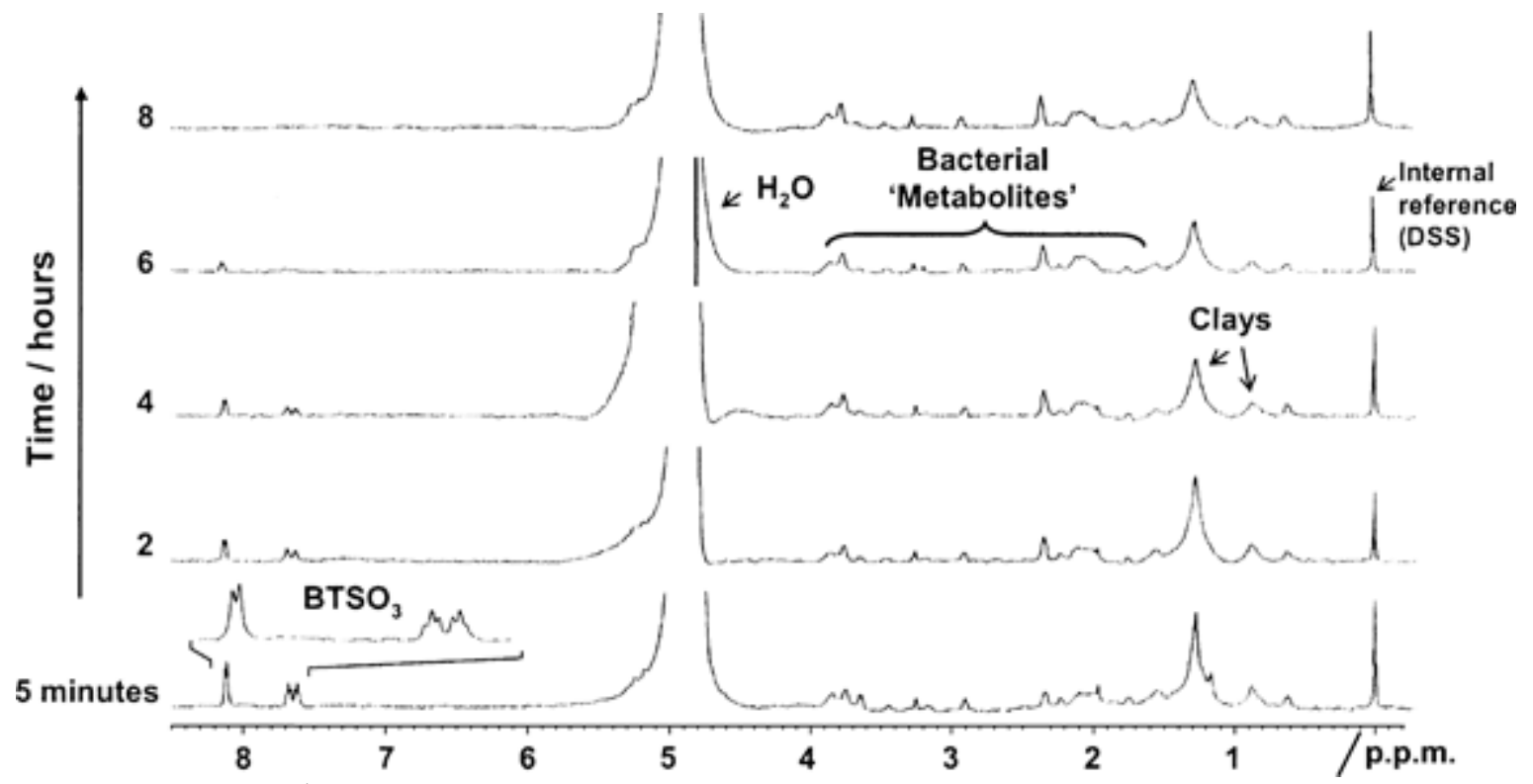

Figure 10 In situ ${ }^{1} \mathrm{H}$ HR-MAS NMR spectra of samples taken at 5 minutes, 2, 4, 6 and 8 hours of incubation of $2 \mathrm{mmol}$ litre ${ }^{-1} \mathrm{BTSO}_{3}$ with resting cells of Rhodococcus erythropolis in the presence of $10 \mathrm{mg}$ anionic clays $\left(\mathrm{Mg}_{3} \mathrm{AlCO}_{3}\right)$.

The analysis of the medium performed directly by ${ }^{1} \mathrm{H}$ HR-MAS without centrifugation showed a similar degradation curve even if only small differences were observed in the degradation compared with results obtained from HPLC or ${ }^{1} \mathrm{H}$ liquid-state NMR of supernatants (Figure 11). The most important change concerned the initial $\mathrm{BTSO}_{3}$ concentration, which is greater in the case of HR-MAS by $15 \%$. Several hypotheses could explain this. (i) A small fraction of the pollutant interacting with the surface was not present after centrifugation and thus neither observed by HPLC nor ${ }^{1} \mathrm{H}$ liquid state NMR. (ii) The interaction affecting $\mathrm{BTSO}_{3}$ and DSS relaxation properties may interfere in quantification. However, $\mathrm{T}_{1}$ of both $\mathrm{BTSO}_{3}$ and DSS decreased by about $10 \%$. Consequently, the relative concentration may not be different. (iii) The spinning rate increased molecular diffusion and the LDH adsorption capacities of one compound compared with batch equilibrium experiments made as described in the OECD Guideline 106 (OECD, 2000) (i.e. not in a HR-MAS NMR rotor). This hypothesis was not consistent with the $\mathrm{T}_{1}$ data and quantification experiments carried out under the same conditions (solid-liquid ratio, spinning rate, temperature). Thus, one of the most probable reasons was the influence of cells. Indeed, the adsorption of $\mathrm{BTSO}_{3}$ or DSS on cells was highly likely as such phenomena have often been described in liquid media. A similar hypothesis would be that cells generate macromolecules that affect adsorption properties of $\mathrm{BTSO}_{3}$ or DSS. In contrast, the ${ }^{1} \mathrm{H}$ HR-MAS NMR showed that the organic compounds interact with the solid at the solid-liquid interface, although adsorption isotherms did not suggest it. This requires further investigation. 


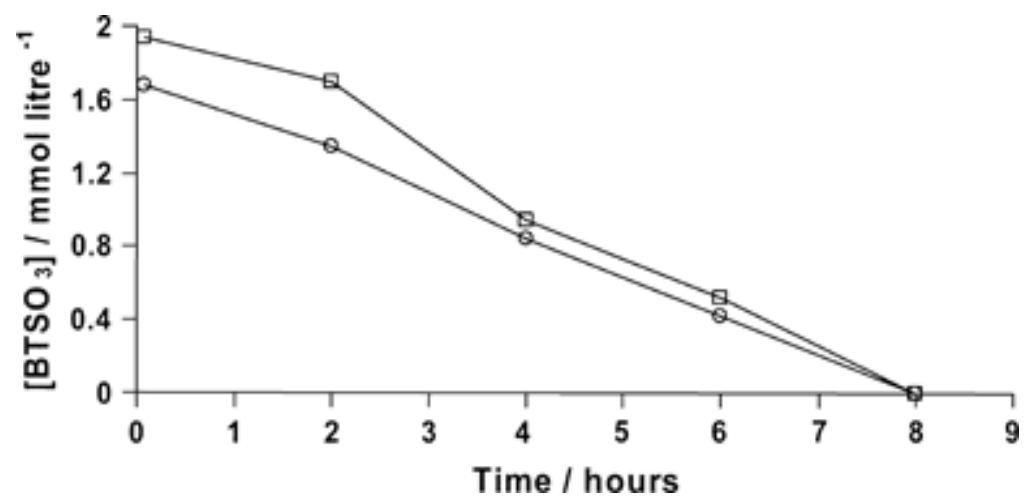

Figure 11 Time course of $\mathrm{BTSO}_{3}$ concentration in the presence of $10 \mathrm{mg}$ of $\mathrm{Mg}_{3} \mathrm{AlCO}_{3} \mathrm{LDH}$ phase determined by ${ }^{1} \mathrm{H}$ liquid state NMR after centrifugation ( $\odot$ ) and by ${ }^{1} \mathrm{H}$ HR-MAS NMR performed directly on the raw medium ( $\square$ ).

\section{Conclusions}

We found that although NMR application is limited to laboratory experiments, it is a unique tool to assess these mechanisms at a molecular level. It appears that (HR) MAS NMR spectroscopy allows direct -'in situ'- observation of the adsorption mechanism at the surface of a colloid. Although observed chemical shifts correspond to an average of several molecules on the NMR time-scale, it clearly appears in this work that the intensity of the detected signals can be analysed in terms of intensity of the interaction involved. The mobility of a pollutant at the surface of solid matrix can thus be assessed; in particular, HRMAS is very promising in differentiating molecular species according to their degree of mobility in hydrated matrices. In the present communication, we have illustrated the potential of various MAS NMR approaches with the case studies of the interactions of three organic pollutants, glyphosate, MCPA and $\mathrm{BTSO}_{3}$, with clay materials. It was shown that CPMAS ${ }^{13} \mathrm{C}$ NMR did not give any conclusive information; in contrast ${ }^{1} \mathrm{H}$ (HR) MAS NMR gave complementary information including $\mathrm{T}_{1}$ values, mobility and quantification of this pollutant loaded at the surface of a solid matrix. Although the NMR technique remains quite insensitive, ${ }^{1} \mathrm{H}$ can be detected relatively easily at natural abundance (vide supra). We have shown that these techniques could be applied both on synthetic anionic clays close to hydrotalcites but also on natural cationic clays such as montmorillonites. This methodology was also successfully applied to monitor the biodegradation of xenobiotics by microorganisms in model soil, directly in situ; in the future it may be interesting to correlate the level of a pollutant loaded at the surface of a soil component - and the interactions involved - to its bioavailability. Dynamic properties of the pollutants, obtained by various relaxation measurement experiments performed on hydrated samples, will be reasonably key points to reach this objective.

\section{Acknowledgements}

N. Haroune was a recipient of a grant from the Ministère de l'Education Nationale et de la Recherche. We greatly acknowledge Martine Sancelme for her precious help in biodegradation experiments.

\section{References}

Ahmad, R., Nelson, P.N. \& Kookana, R.S. 2006. The molecular composition of soil organic matter as determined by ${ }^{13}$ C NMR and elemental analyses and correlation with pesticide sorption. European Journal of Soil Science, 57, 883-893.

Besse, P., Combourieu, B., Boyse, G., Sancelme, M., De Wever, H. \& Delort, A.-M. 2001. Long-range ${ }^{1} \mathrm{H}_{-}{ }^{15} \mathrm{~N}$ heteronuclear shift correlation at natural abundance: a tool to study benzothiazole biodegradation by two Rhodococcus strains. Applied and Environmental Microbiology, 67, 1412-1417.

Bilski, P., Sergeev, N.A. \& Wasicki, J. 2002. Solid echo in the slow-motion region. Effects of the finite pulse widths. Solid State Nuclear Magnetic Resonance, 22, 1-18.

Bonin, J.L. \& Simpson, M.J. 2007. Variation in phenanthrene sorption coefficients with soil organic matter fractionation: the result of structure or conformation? Environmental Science and Technology, 41, 153-159.

Combourieu, B., Inacio, J., Delort, A.M. \& Forano, C. 2001. Differentiation of mobile and immobile pesticides on anionic clays by ${ }^{1} \mathrm{H}$ HR MAS NMR spectroscopy. Chemical Communications, 21, 2214-2215.

Combourieu, B., Inacio, J., Taviot-Gueho, C., Forano, C. \& Delort, A.-M. 2005. Pesticides mobility studied by nuclear magnetic resonance. In: Environmental Chemistry. Green Chemistry and Pollutants in Ecosystems (eds E. Lichtfouse, J. Schwarzbauer \& D. Robert), pp. 463-472. Springer-Verlag, Berlin.

Cornejo, J. \& Jamet, P. (eds) 2000. Pesticide/Soil Interactions. INRA Edition, Paris. 
Damonte, M., Torres Sánchez, R.M. \& dos Santos Afonso, M. 2006. Some aspects of the glyphosate adsorption on montmorillonite and its calcined form. Applied Clay Science, 36, 86-94.

De Wever, H., Besse, P. \& Verachtert, H. 2001. Microbial transformations of 2-substituted benzothiazoles. Applied Microbiology and Biotechnology, 57, 620-625.

Duer, M.J. 2002. Dipolar coupling: its measurements and uses. In: Solid-State NMR Spectroscopy Principles and Applications (ed. M.J. Duer), pp. 86-97. Blackwell Science, Oxford.

Emery, E.F., Junk, T., Ferrell, R.E., De Hon, R. \& Butler, L.G. 2001. Solid-state ${ }^{2}$ H MAS NMR studies of TNT absorption in soil and clays. Environmental Science and Technology, 35, 2973-2978.

Gilchrist, G.F.R., Gamble, D.S., Kodama, H. \& Khan, S.U. 1993. Atrazine interactions with clay minerals: kinetics and equilibria of sorption. Journal of Agricultural and Food Chemistry, 41, 1748-1755.

Gimsing, A-.L., Sørensen, J.C., Strobel, B.W. \& Hansen, H.C.B. 2007. Adsorption of glucosinolates to metal oxides, clay minerals and humic acid. Applied Clay Science, 35, 212-217.

Golding, C.J., Smernik, R.J. \& Birch, G.F. 2005. Investigation of the role of structural domains identified in sedimentary organic matter in the sorption of hydrophobic organic compounds. Environmental Science and Technology, 39, 3925-3932.

Haroune, N. 2003. Métabolisme de benzothiazoles par des souches de Rhodococcus: étude par RMN in situ. Thèse d'Université, Université Blaise Pascal, Clermont-Ferrand, France.

Inacio, J., Taviot-Gueho, C., Forano, C. \& Besse, J.P. 2001. Adsorption of MCPA pesticide by MgAl-layered double hydroxides. Applied Clay Science, 18, 255-264.

Knicker, H. 2003. Incorporation of ${ }^{15} \mathrm{~N}$-TNT transformation products into humifying plant organic matter as revealed by oneand two-dimensional solid state NMR spectroscopy. Science of the Total Environment, 308, 211-220.

Kohl, S.D., Toscano, P.J., Hou, W.H. \& Rice, J.A. 2000. Solid-state ${ }^{19}$ F NMR investigation of hexafluorobenzene sorption to soil organic matter. Environmental Science and Technology, 34, 204-210.

Laird, D.A. 2004. Reactions of organic molecules with smectite surfaces in aqueous systems. Acta Mineralogica-

Petrographica, Series 4 (Abstract), pp. 64-68.

Laird, D.A. \& Sawhney, B.L. 2002. Reactions of pesticides with soil minerals. In: Soil Mineralogy with Environmental Application. SSSA Book series (ed. S. R. Goldberg), 7, pp. 765-790. Soil Science Society of America, Madison, Wisconsin. Matthes, W. \& Kahr, G. 2000. Sorption of organic compounds by Al- and Zr-hydroxy-intercalated and pillared bentonite. Clays and Clay Minerals, 48, 593-602.

Miles, C.J. \& Moye, H.A. 1988. Extraction of glyphosate herbicide from soil and clay minerals and determination of residues in soils. Journal of Agricultural and Food Chemistry, 36, 486-491.

Nanny, M.A. \& Maza, J.P. 2001. Noncovalent interactions between monoaromatic compounds and dissolved humic acids: a deuterium NMR $\mathrm{T}_{1}$ relaxation study. Environmental Science and Technology, 35, 379-384.

Nanny, M.A., Minear, R.A. \& Leenheer, J.A. 1998. Nuclear Magnetic Resonance in Environmental Chemistry. Oxford University Press, New York.

OECD, 2000. Test 106: Adsorption-desorption using a batch equilibrium method. In: OECD Guidlines for the Testing of Chemicals. OECD Test Guidline 106, OECD Publications, Paris.

Oren, A. \& Chefetz, B. 2005. Sorption-desorption behavior of polycyclic aromatic hydrocarbons in upstream and downstream river sediments. Chemosphere, 61, 19-29.

Piotto, M., Bourdonneau, M., Furrer, J., Bianco, A., Raya, J. \& Elbayed, K. 2001. Destruction of magnetization during TOCSY experiments performed under magic angle spinning: effect of radial $\mathrm{B}_{1}$ inhomogeneities. Journal of Magnetic Resonance, 149, 114-118.

Reemtsma, T., Weiss, S., Mueller, J., Petrovic, M., Gonzales, S., Barcelo, D. et al. 2006. Polar pollutants entry into the water cycle by municipal wastewater: a European perspective. Environmental Science and Technology, 40, 5451-5458.

Seger, M.R. \& Maciel, G.E. 2006. NMR investigation of the behavior of an organothiophosphate pesticide, chlorpyrifos, sorbed on montmorillonite clays. Environmental Science and Technology, 40, 797-802.

Sheals, J., Sjöberg, S. \& Persson, P. 2002. Adsorption of glyphosate on goethite: molecular characterization of surface complexes. Environmental Science and Technology, 36, 3090-3095.

Simpson, A.J., Kingery, W.L., Shaw, D.R., Spraul, M., Humpfer, E. \& Dvortsak, P. 2001. The application of ${ }^{1}$ H HR-MAS NMR spectroscopy for the study of structures and associations of organic components at the solid-aqueous interface of a whole soil. Environmental Science and Technology, 35, 3321-3325.

Simpson, A.J., Simpson, M.J., Kingery, W.L., Lefebvre, B.A., Moser, A., Williams, A.J. et al. 2006. The application of ${ }^{1}$ H high-resolution magic-angle spinning NMR for the study of clay-organic associations in natural and synthetic complexes. Langmuir, 22, 4498-4503.

Smernik, R.J., Kookana, R.S. \& Skjemstad, J.O. 2006. NMR characterization of ${ }^{13}$ C-benzene sorbed to natural and prepared charcoals. Environmental Science and Technology, 40, 1764-1769.

Spark, K.M. \& Swift, R.S. 2002. Effect of soil composition and dissolved organic matter on pesticide sorption. Science of the Total Environment, 298, 147-161.

Vereecken, H. 2005. Mobility and leaching of glyphosate: a review. Pest Management Science, 61, 1139-1151. 